\title{
La parlamentarización peruana (200I-20I6). Presidencialismo y sistema de partidos
}

\section{The Peruvian parliamentarization (200I-20I6). Presidentialism and party system}

doi: http://dx.doi.org/10.32870/espiral.v26i74.7050 Ignacio García Marín

\section{Resumen}

Este artículo analiza las presidencias de los peruanos Alejandro Toledo (200I-2006), Alan García (2006-20I I) y Ollanta Humala (20II-20I6), en relación con la composición de sus gabinetes, la producción legislativa y la estabilidad de los grupos parlamentarios. El objetivo es identificar el equilibrio de poderes entre el Ejecutivo y el Legislativo en Perú durante dichos últimos mandatos. Se revisa cómo la baja institucionalización del sistema de partidos y la creciente fragmentación del Congreso durante estos periodos habrían afectado a ambos poderes de distinta manera, otorgando al Congreso una mayor capacidad de condicionar al Ejecutivo en lo que se refiere a su composición y estabilidad y dándole un creciente rol como institución legisladora, a diferencia de lo sucedido en décadas previas. Por ello, se concluye que el diseño institucional del presidencialismo en Perú, así como su sistema de partidos, han llevado a un creciente protagonismo del Congreso en detrimento del Poder Ejecutivo.

Palabras clave: presidencialismo, sistema de partidos, parlamentarización, relaciones

Ejecutivo-Legislativo, Perú.

\begin{abstract}
This article analyzes the Peruvian presidencies of Alejandro Toledo (200 I-2006), Alan García (2006-20II) and Ollanta Humala (20II-20I6), about the composition of their cabinets, the legislative production, and the stability of the parliamentary groups. The objective is to identify the balance between the Executive and Legislative powers at Peru on those last terms. In this sense, the low institutionalization of the party system and the increasing fragmentation of the Congress affected both power branches, but in different ways. The Congress obtained a greater capacity to determine the Executive in regard to its growing role as a legislating institution and the cabinet stability, a difference from the previous decades. We concluded that the institutional design of Peruvian presidentialism, as well as it party system, have empowered the Congress to the detriment of the Executive.
\end{abstract}

Keywords: Presidentialism, party system, parliamentarization, Executive-Legislative relations, Peru.

•Profesor de la Universidad Anáhuac, México. ORCID: http://orcid.org/0000-0003-2754-1934 nachogarciamarin08@gmail.com

Fecha de recepción: 17 de abril de 2018. Fecha de aceptación: 02 de octubre de 2018 . 


\section{Introducción}

La salida de Alberto Fujimori de la Presidencia de Perú, en noviembre de 2000, dio fin a una década de autoritarismo competitivo en dicho país (Levitsky y Way, 2010; Levitt, 2012). Durante su periodo, el mandatario había impulsado una nueva constitución (la actual, de 1993), dominado la política a través de su propia mayoría parlamentaria y, además, gobernado mediante la ejecución de fuerza desde el Ejecutivo hacia el Legislativo (Levitt, 2012, p. 29). Sin embargo, la presente investigación defiende que el diseño institucional emanado de dicha constitución tiende a parlamentarizar el sistema político peruano en un escenario de minoría oficialista y baja institucionalización del sistema de partidos, condiciones ambas dadas durante el periodo de estudio del presente artículo: 2001-2016.

\section{El sistema presidencial peruano}

Con respecto a las principales características del sistema presidencial peruano, hay que precisar que a la elección directa, separada y concurrente del jefe del Estado y los legisladores en dicho país, se suma un mandato fijo del primero y su irresponsabilidad ante la Cámara (amparada en los artículos 113 y 114 de la constitución política de Perú -CPP-). Igualmente, hay que recordar que el presidente de la república es a su vez jefe del Estado y personificación de la nación (artículo 110 de la CPP), y que no se permite su reelección inmediata (artículo 112 de la CPP), posibilidad que sí contemplaba la constitución original de $1993 .{ }^{1} \mathrm{El}$ presidente es, además, jefe de Gobierno (artículo 188, inciso

I. La posibilidad de reelección se modificó a través del artículo I de la Ley 27365 , siendo efectiva el 5 de noviembre de 2000, al comienzo de la administración de Valentín Paniagua (2000-200I), quien, como presidente del Congreso, sustituyó a Fujimori tras su salida del país. 
3 de la CPP), lo que genera un "carácter unipersonal del Ejecutivo" (Pease García, 2010, p. 10), aunque dicho poder lo integren también otras instituciones.

Todos estos rasgos son los tradicionales del modelo presidencial como forma de Gobierno en el continente americano, a los que debe añadirse en el caso de Perú la existencia de dos vicepresidentes con muy escasas atribuciones. En concreto, el hecho de que el presidente sea también jefe de Gobierno es una cuestión que no ha estado exenta de controversia, pues como resalta Rubio Correa (1999, pp. 316-317), puede llevar a la confusión entre dos instituciones de primer orden: la jefatura del Estado y el Gobierno.

Sin embargo, el sistema de Gobierno peruano tiene algunas especificaciones propias, las cuales, como se mostrará posteriormente, si de por sí tienden a incidir notablemente en las relaciones entre los poderes del Estado, lo hacen especialmente si entran en juego las dinámicas de un sistema de partidos poco institucionalizado y tendiente a la fragmentación en el Congreso, como ha sido el caso en el periodo bajo análisis.

En primer lugar, está el caso del presidente del Consejo de Ministros (PCM), emanado del artículo 121 de la CPP, frecuentemente denominado primer ministro o premier en el país. Se trata de una figura habitual en los regímenes semipresidencialistas y parlamentarios. Su nombramiento necesita, para el caso peruano, la aprobación del Congreso tras treinta días desde su toma de posesión, aunque es nombrado y propuesto por el presidente de la república. En el caso peruano, apenas guarda semejanzas con los primeros ministros parlamentarios, ya que "no toma ninguna decisión significativa por el peso decisorio del presidente de la república, siendo más bien sus funciones de coordinación y control intraórgano" (Rubio Correa, 1999, p. 391). 
El PCM puede ser apartado de su cargo por el Legislativo si una moción de censura es presentada y ganada por sus proponentes, o bien, si una moción de confianza es perdida ante la Cámara (artículos 132 y 133 de la CPP). No se requiere, además, de un candidato alternativo para su cese, por lo que no se trata de una moción constructiva. Asimismo, si la moción se produce con éxito, el PCM dimite junto a todos los ministros, dándose una crisis total de gabinete (artículo 134 de la CPP). A su vez, el Consejo de Ministros forma "un órgano del Poder Ejecutivo que cogobierna en muchos asuntos significativos con el presidente de la república" (Rubio Correa, 1999, p. 392).

En segundo lugar, debe destacarse otra facultad propia de los regímenes parlamentarios, que es la capacidad de presidente de disolver el Congreso, en este caso bajo una condición necesaria, pues el mandatario estará habilitado para ejercerla si el Legislativo "ha censurado o negado su confianza a dos Consejos de Ministros. El decreto de disolución contiene la convocatoria a elecciones para un nuevo Congreso" (artículo 134 de la CPP), ${ }^{2}$ con la particularidad de que, a diferencia de un régimen parlamentario, tanto el presidente de la república como los diputados tienen distintas legitimidades de origen al respecto.

Los dos elementos descritos subrayan la matización de la separación de los poderes que el presidencialismo instaura como uno de sus fundamentos y que la propia carta magna peruana establece en su articulado (artículo 43). Además, la disolución del Congreso explicada no lleva aparejada la entrada en funciones del jefe del Estado ni una nueva fecha para la elección de su sucesor, lo que acrecienta el poder de amenaza del presidente sobre la Cámara baja. Sin embargo, sí contiene algunas restricciones, como la 
no disolución en el último año del mandato presidencial salvo en estado de emergencia, con la comisión permanente siempre funcionando.

Por otro lado, el sistema también contempla que las elecciones legislativas deben llevarse a cabo antes de los cuatro meses después de la disolución, sin que sea posible modificar la legislación electoral que exista. En caso de no realizarse los comicios, los diputados recuperarían sus escaños y plenas facultades, y además se produciría la destitución del Consejo de Ministros (artículo 136 de la CPP). El mandato de los nuevos congresistas durará hasta que finalice el del presidente de la república, a fin de que las elecciones generales sean siempre concurrentes en cuanto a la elección de legisladores y jefe del Estado (al menos en su primera vuelta).

En efecto, las elecciones de diputados y presidente, aun siendo directas y separadas, se producen en un mismo día, haciéndose coincidir la primera vuelta presidencial con las legislativas (artículo 20 de la Ley Orgánica de Elecciones 26859 -LOE-). Esta cuestión no es irrelevante, pues, como señala Tuesta (2010, p. 91), esta coincidencia buscaba generar un efecto de arrastre de la hipotética popularidad de los candidatos a la presidencia que beneficiara a sus candidatos al Congreso. Sin embargo, ninguno de los presidentes peruanos que ha habido en el siglo XXI ha contado con bancadas oficialistas que conformaran mayorías absolutas en la Cámara, y desde 1980 esto sólo sucedió en tres ocasiones. ${ }^{3}$

Por otra parte, la moción de confianza puede además ser empleada como una estrategia política, toda vez que, siguiendo a Rubio Correa (1999, p. 448), puede ser un ulti-

3. Fernando Belaúnde Terry, en 1980, con su organización política Alianza Popular, tuvo noventa y ocho diputados de ciento ochenta; Alan García, en su primer mandato presidencial en 1985, tuvo ciento siete escaños sobre los mismos ciento ochenta; y Alberto Fujimori, en 1995, tuvo sesenta y siete escaños sobre ciento veinte posibles a través de la organización Cambio 90. 
mátum del Ejecutivo ante el Congreso para que acepte sus planeamientos políticos, ya que puede venir acompañada de una iniciativa ministerial, bien sobre un ministro, bien sobre todo el Consejo de Ministros. No cabe duda de que, en este segundo caso, el rechazo generaría una crisis total de gabinete, lo que habilitaría la disolución congresual y trasladaría a la opinión pública el choque entre ambos poderes. Se trata, por cierto, de una novedad de la constitución de 1993 con respecto a la de 1979 que puede limitar la acción de control y castigo por parte del Legislativo hacia el Ejecutivo.

Esta potestad no fue empleada por los presidentes Toledo (2001-2006), García (2006-2011) y Humala (2011-2016), a pesar de que durante el Gobierno de este último se especuló con esta posibilidad en torno al oficialismo. ${ }^{4}$ En esta misma línea pueden ir las palabras de Sartori (1996): "la capacidad de disolver el parlamento otorga más poderes al presidente, pero por lo general se sobrestima la eficacia de este disuasivo" (p. 102). Es dable afirmar que posiblemente el desgaste político que sufriría el presidente de la república por llevar a cabo esta acción le orienta a abstenerse, perdiendo con ello la capacidad de disuasión. Pese a todo, en escenarios de elevada polarización ideológica y confrontación partidaria, puede volverse una herramienta a emplear por parte de la cabeza del Ejecutivo.

El presidente de la república cuenta con iniciativa legislativa (artículo 107 de la CPP), la cual además tiene carácter prioritario si otorga urgencia a los proyectos de ley presentados por terceros proponentes (artículo 105 de la CPP) y, para ciertos temas, cuenta con iniciativa exclusiva. Estrictamente hablando, y como subraya Rubio Correa (1999, p.

4. Dada la moción de censura que cesó a la primera ministra Ana Jara, el Ejecutivo de Humala pudo haber planteado mociones de confianza para forzar apoyos congresuales puntuales, por ejemplo, para la aprobación de leyes autoritativas que le habilitaran para emitir decretos legislativos, pero no se llegó a materializar dicha acción. 
220), el proyecto de ley debe contar con la aprobación del Consejo de Ministros, por lo que corresponde más bien al Poder Ejecutivo.

Este hecho, no obstante, no se encuentra en el modelo presidencial estadounidense, base del modelo peruano, ya que el presidente de los Estados Unidos, por ejemplo, no cuenta con esta potestad, por mucho que pueda ser razonablemente sorteada con el apoyo de su bancada o de algún legislador afín.

El Congreso peruano es monocameral, una diferencia con respecto a la constitución previa de 1979 y otra respecto al modelo estadounidense. Este cambio no fue inocente, pues la carta magna de 1993 limitaba la acción de las regiones, además de establecer únicamente ciento veinte escaños (desde 2006 son ciento treinta), con lo que para algunos autores como García Belaunde (2008, p. 107) se buscaba un contrapeso limitado al Ejecutivo. A ello debe sumarse que la facultad presidencial de disolución del Congreso hace que el mandato de los legisladores no tenga un carácter plenamente fijo, aunque las facultades del Legislativo en cuanto al juicio político le dan un peso de poder de nivel intermedio en relación con otros países de Latinoamérica (Alcántara, García Montero, y Sánchez López, 2005).

Como ya se ha mencionado, el presidente no puede ser reelegido de manera inmediata, por lo que tiene que esperar al menos otro quinquenio presidencial, sin límite alguno de mandatos presidenciales. Esta es una novedad con respecto al texto original de 1993, ya que entonces se permitía la reelección inmediata por hasta dos mandatos consecutivos totales, a lo que se añadió la controvertida reforma que Fujimori impulsó en 1996, que le permitió presentarse por tercera vez a las elecciones. La Ley 27365 del año 2000 estableció la limitación actual. A este respecto, y como señala Sartori (1996, p. 191), esta modificación no es irrelevante, pues considera que los presidentes sin capacidad de 
reelección tienden a ser más débiles porque tienen menor capacidad de compensar favores políticos.

Lo hasta aquí descrito señala los principales rasgos del sistema presidencial peruano desde un punto de vista normativo. Algunos de estos elementos, como el de la existencia del PCM, llevan en el ordenamiento jurídico peruano desde 1856 (García Belaunde, 2009), lo que ha dado lugar al denominado proceso de parlamentarización del presidencialismo peruano, el cual culmina, se puede decir, con la presente constitución. Este es un punto de partida, o al menos de evolución, distinto al de los orígenes del constitucionalismo peruano, ya que, según señalaba el artículo 29 de la carta magna de 1823, ninguno de los tres poderes podrá ejercer jamás ninguna de las atribuciones de los otros dos. Como se verá posteriormente, la capacidad de incidencia en la actividad legislativa del Ejecutivo es significativa, así como la del Congreso de cuestionar la estabilidad del gabinete, incluyendo la figura presidencial.

Por tanto, y resultado de todo ello, puede decirse que la separación entre los poderes Ejecutivo y Legislativo en Perú es menos rígida que en el modelo presidencial ideal, por mucho que este, como muestra su práctica, produzca continuas interferencias entre los poderes a fin de que se frenen y controlen entre sí. Se dan, pues, unas evidentes hibridación y mezcla de competencias.

No obstante, algunos autores como Sartori (1996, p. 188) sitúan igualmente al sistema peruano como un presidencialismo puro a partir de su diseño institucional, aunque existan las variaciones anteriormente descritas. Otros, como Belaunde García (2009), lo califican de presidencialismo atenuado, dado el control que el PCM directamente y el parlamento indirectamente tienen sobre el presidente de la república. García Montero (2009) igualmente lo ubica así, empleando como referencia el diseño institucional. Por el contrario, Levitt (2012), al menos para un periodo previo 
(1985-2006), señala que "de muy distintas maneras, las instituciones formales del Perú fomentan el hiperpresidencialismo" (p. 4).

La presente investigación, sobre los resultados obtenidos en el análisis del periodo 2001-2016, entiende que se ha producido una debilitación del Poder Ejecutivo en favor del Congreso, tanto por el diseño institucional como por el sistema de partidos.

\section{El sistema de partidos peruano entre 2001 y 2016}

El sistema de partidos peruano ha destacado por una baja institucionalización, una elevada fragmentación y una muy alta volatilidad electoral. Además, el transfuguismo o cambio de grupo parlamentario de los diputados a lo largo de las legislaturas ha sido muy elevado. A esto se pueden añadir la dificultad de los partidos para penetrar por todo el territorio nacional, la mala calificación que reciben por parte de la opinión pública, y la importancia de los líderes partidarios sobre estas organizaciones. Todo ello ha dibujado un escenario por el cual varios autores han calificado al sistema político peruano de presidencialismo sin partidos, como Lanzaro (2012) y Nohlen (2013) han afirmado, o de democracia sin partidos (Levitsky y Cameron, 2003).

La gran transformación del sistema de partidos llegó a través del autogolpe ${ }^{5}$ fujimorista de 1992, que tuvo apoyo militar (Tuesta, 2010, p. 48; Alcántara, 2013, p. 493), aunque el desgaste de las organizaciones partidarias ya era evidente años antes a la luz de los datos mostrados y del decreciente desempeño en las elecciones locales de 1989. A esto deben sumarse los conflictos entre y dentro de los partidos ajenos al fujimorismo (Tanaka, 2005a, p. 32).

5. Mediante el cual el presidente Alberto Fujimori cerró el Congreso, intervino el Poder Judicial y comenzó a legislar por decreto. 
Durante los ochenta, el sistema de partidos había colapsado (Tanaka, 1998, 2002 y 2005b), lo que había desplazado a organizaciones con arraigo social hasta entonces considerable. El discurso antipolíticos y antipartidos caló en la sociedad, lo que fue empleado por el nuevo presidente en la propia campaña electoral. El autogolpe, eso sí, contó con legitimidad interna gracias a los éxitos del fujimorismo contra Sendero Luminoso y otros grupos terroristas, así como por la marcha de la economía, pero no tuvo apoyos internacionales, por lo que necesitó una constitución (Tuesta, 2010).

Como destaca Tanaka (2005a, p. 34), dada la popularidad que fue adquiriendo Fujimori en la sociedad, así como el desgaste de los partidos hasta entonces existentes y la mala imagen del Congreso y el Poder Judicial, el Ejecutivo tendió a empoderarse con relación a las demás instituciones del Estado bajo el ya mencionado discurso antipartidos y antipolíticos, anulando los mecanismos de control horizontal.

Poco después, con las elecciones generales de 1995, se produjo el gran reforzamiento del cambio político iniciado en 1990 en materia de sistema de partidos. Alberto Fujimori ganó las elecciones presidenciales con una amplia diferencia en primera vuelta: $64.28 \%$ de los votos válidos, esto con su partido Cambio 90 y la alianza con Nueva Mayoría. En segundo lugar electoral, se situó el exsecretario general de Naciones Unidas, Javier Pérez de Cuéllar, quien alcanzó el $21.53 \%$ de los votos con el partido Unión por el Perú (UPP). En tercer lugar, quedó la organización política Alianza Popular Revolucionaria Americana (APRA), bajo la candidatura de Mercedes Cabanillas, con un exiguo 4.11\% de votos. La volatilidad presidencial agregada se situó en el 40.24\% (Meléndez, 2012), lo cual mostró nuevamente valores elevados en este rubro.

Así, la década de los noventa estuvo dominada en el plano político peruano por Alberto Fujimori y su organización par- 
tidaria, que se había conformado como la fuerza hegemónica del Congreso (Tuesta, 2005, p. 183). Los partidos acentuaron durante estos años el carácter personalista, lo que los configuró en ocasiones como meros vehículos electorales para sus candidatos presidenciales (Levitsky y Cameron, 2003; Tuesta, 2010). Además, continuó la baja calificación de los mismos por parte de los ciudadanos (Levitt, 2012), así como elevadas tasas de volatilidad, que adquirieron un nuevo matiz: el voto ya no se repartió entre fuerzas partidarias ya existentes en el Parlamento, sino entre estas y nuevas organizaciones y candidaturas independientes, por lo que la volatilidad tuvo un creciente carácter externo. Todo ello estuvo rodeado del ya mencionado discurso antipartidos y antipolítica, que se lanzaba desde la propia Presidencia de la república (Meléndez, 2006, p. 4), y de una práctica política autoritaria (Levitsky y Way, 2010; Alcántara, 2013, p. 480). También de un evidente apoyo popular, como las elecciones mostraron.

Sin embargo, las elecciones del 2000 significaron el fin del fujimorismo en la Presidencia. Ayudado por la conocida interpretación auténtica de la constitución (Contreras y Zuloaga, 2014), Alberto Fujimori se presentó nuevamente a las elecciones, a pesar de que ello suponía su tercer mandato consecutivo. ${ }^{6}$ Ganó la primera vuelta, con un $49.87 \%$ de los votos, bajo su nueva fórmula electoral, Perú 2000, seguido del ascendente Alejandro Toledo, con un 40.24\%, bajo Perú Posible (PP). Partidos tradicionales como el APRA y Acción Popular (AP) obtuvieron resultados marginales, ambos por debajo del $2 \%$ de votos válidos. En la segunda vuelta, las distancias se ensancharon entre los dos princi-

6. En aquel momento, la constitución permitía la reelección inmediata por una única ocasión, y posteriormente, en 200 I, la misma fue modificada para no permitirla. El Tribunal Constitucional le permitió un hipotético tercer mandato a Fujimori al entender que la limitación de reelección comenzaba una vez que las elecciones presidenciales se realizaban tras la vigencia de la constitución de 1993. 
pales contendientes, con resultados de $74.33 \%$ y $25.67 \%$, respectivamente. La volatilidad presidencial se situó en el $58.3 \%$. No obstante, Toledo trató de retirarse de la segunda vuelta alegando falta de limpieza en el proceso, aunque las instituciones electorales le denegaron la solicitud.

En lo concerniente al Legislativo, el fujimorismo se quedó cerca de controlar de inicio la Cámara, pues obtuvo cincuenta y dos de los ciento veinte escaños posibles. El PP se ubicó en veintinueve curules; Somos Perú y el Frente Independiente Moralizador (FIM) en nueve cada uno; el APRA en seis; y los restantes quince se dividieron entre pequeños grupos parlamentarios, como los de AP y UPP. La volatilidad parlamentaria se situó en un 41.6\% (Meléndez, 2012), el número efectivo de partidos (NEP) en 2.42 y el número efectivo de partidos parlamentarios (NEPP) en 3.97.

Apenas un año después, Alberto Fujimori renunció a la presidencia tras varios escándalos de corrupción, especialmente por lo concerniente a las gestiones de su asesor presidencial Vladimiro Montesinos en el soborno a congresistas y empresarios en lo que se llamó los vladivideos. ${ }^{7}$ Fue sustituido finalmente en el cargo, y tras un proceso de destitución por parte del Legislativo, fue remplazado por Valentín Paniagua, entonces presidente del Congreso y durante cuyo mandato de un año fueron emprendidas diversas reformas ya comentadas previamente, como la relativa a la imposibilidad de la reelección inmediata para presidentes. En todo caso, Tanaka (2005a, p. 31) señala que las diferencias y los conflictos internos en el fujimorismo fueron algunos de los causantes del fin de su Presidencia.

7. Los vladivideos fueron grabaciones realizadas por el propio Vladimiro Montesinos en los que se mostraba el acuerdo de compra de voluntades políticas y económicas a cambio de ciertos apoyos por parte del Ejecutivo de Alberto Fujimori. Las grabaciones fueron obtenidas por algunos diputados del FIM con la ayuda de integrantes del servicio peruano de inteligencia, y prestadas a medios de comunicación para su exposición. 
En las elecciones generales de 2001, el sistema de partidos mutó, al pasar del dominio de una organización hegemónica (el fujimorismo) a un multipartidisimo moderado (Tuesta, 2005, p. 183). En dichos comicios, Alejandro Toledo (PP) se hizo con la Presidencia, tras obtener un 52.71\% de los votos válidos y capitalizar el creciente apoyo y popularidad que había ido recabando en los años previos. Su rival en la segunda vuelta fue Alan García, quien volvió a liderar el APRA, con un $47.29 \%$ de los votos en el balotaje. Con respecto a la primera vuelta, en tercer lugar se situó Lourdes Flores, mediante la coalición Alianza Electoral Unidad Nacional, de ideología predominantemente conservadora y liberal, que reunió a partidos como el Partido Popular Cristiano (PPC) y Solidaridad Nacional. Flores obtuvo un $24.3 \%$ de los votos, lo que le impidió pasar a la segunda vuelta. La volatilidad presidencial en dichos comicios se situó de nuevo en un valor muy alto: $48.25 \%$.

Con respecto a las legislativas, el PP obtuvo cuarenta y cinco escaños, siendo la primera fuerza en el Congreso y, aunque lejos de la mayoría absoluta, esto le permitió cierto dominio de la actividad legislativa, especialmente por la fragmentación de la oposición. Por su parte, el APRA obtuvo veintiocho diputados, mostrando de nuevo cierta fortaleza partidaria como organización estable, y Unidad Nacional obtuvo diecisiete, por lo que los tres primeros puestos en las presidenciales se repitieron en el terreno del Congreso. La volatilidad parlamentaria se situó en el $62.1 \%$, el NEP en 3.72 y el NEPP en 4.37 .

Posteriormente, en 2006, Alan García (APRA) alcanzó su segundo mandato presidencial, a pesar de quedar segundo en la primera vuelta contra Ollanta Humala (UPP). El candidato aprista obtuvo en el balotaje un $52.62 \%$ de los votos, contra $47.37 \%$ del nacionalista Humala. En tercer lugar, se situó Lourdes Flores (Unidad Nacional), con un 23.81\% en la primera ronda, seguida de Martha Chávez (Alianza 
por el Futuro), con un $7.43 \%$, lo que supuso la progresiva recuperación del legado electoral del fujimorismo. La volatilidad presidencial en dichos comicios fue de un $35.65 \%$.

En las elecciones legislativas de dicho año, la coalición que obtuvo más escaños fue UPP, en consonancia con los resultados presidenciales de la primera vuelta, al alcanzar los cuarenta y cinco lugares. Le siguieron el APRA, con treinta y seis curules, Unidad Nacional con diecisiete, y Alianza para el Futuro con trece. De entre los restantes, es destacable el hundimiento de PP, que alcanzó únicamente dos escaños. La volatilidad parlamentaria se situó en el 35.65\% (Meléndez, 2012). Por su parte, el NEP fue de 4.54 y el NEPP de 3.78.

En 2011 llegó a la Presidencia Ollanta Humala, a través del Partido Nacionalista Peruano (PNP) y apoyado por otras organizaciones de izquierda. Su política pública mantuvo los consensos en materia económica, lo que quizá puede explicar parcialmente la gran inestabilidad que su grupo parlamentario vivió en el Congreso, ya desde los comienzos del quinquenio. El nuevo presidente alcanzó un 51.45\% de los votos, superando por estrecho margen en el balotaje a Keiko Fujimori (Fuerza 2011), que alcanzó el 48.55\%. En tercer lugar, en primera ronda, se situó Pedro Pablo Kuczynski (también conocido como PPK) con un 18.52\% de los votos, obtenidos a través de la Alianza por el Gran Cambio, que aglutinaba a fuerzas conservadoras como el PPC. Por debajo de él, se situó Alejandro Toledo (PP), quien intentó alcanzar un segundo mandato presidencial pero apenas logró el 15.64\% de los votos, a pesar de liderar las encuestas durante un largo tiempo. La volatilidad presidencial siguió a la baja, situándose en el 24\% (Meléndez, 2012), valor elevado, aunque el menor alcanzado en el país desde 1980.

Con respecto al Congreso, la coalición oficialista Gana Perú, dominada por el PNP, fue la gran ganadora en un 
principio, al hacerse de cuarenta y siete de los ya entonces ciento treinta escaños. En segundo lugar, quedó el fujimorismo, a través de Fuerza 2011, con treinta y siete curules, seguido por PP con veintiuna, Alianza para el Gran Cambio con doce, Solidaridad Nacional con nueve, y finalmente, la debacle aprista, con únicamente cuatro escaños. Al igual que en las elecciones presidenciales, la volatilidad tendió a la baja, situándose en un 25.8\% (Meléndez, 2012), también la menor desde 1980. El NEP se situó en 4.46 y el NEPP en 3.97, ambos al alza.

Como balance global, debe destacarse que la experiencia desde 2001 muestra que los presidentes han sido electos tras presentarse al menos una segunda vez a las elecciones. Este fue el caso de Alejandro Toledo, Alan García y Ollanta Humala, los tres últimos mandatarios. También es destacable la frecuente minoría oficialista en el Congreso, hecho con el que incluso Fujimori tuvo que convivir durante gran parte de su década autoritaria.

Por otro lado, la volatilidad agregada fue muy elevada, aunque con tendencia a la baja y con mantenimiento de su carácter externo, hecho que coincide con las décadas previas. En efecto, entre 1980 y 2011, la volatilidad presidencial en Perú se situó en un 56.82\%, la legislativa en $60.36 \%$, y la combinación de ambas en $58.59 \%,{ }^{8}$ valores que son los más altos de América Latina en periodos similares: la volatilidad agregada media de Argentina (1983 a 2011) fue de 33.56\%; la de Chile (1989 a 2009) de 22.85\%; la de Colombia (1982 a 2010) de 31.32\%; y la de Uruguay (1994 a 2009) de $14.29 \% .^{9}$

Es dable decir que la volatilidad se mantuvo desde 1990 con importante carácter externo por la inestabilidad de los

8. Según datos proporcionados por la Oficina Nacional de Procesos Electorales (ONPE), en poder del autor.

9. Según datos proporcionados por el Observatorio de Instituciones Representativas (OIR), y considerando volatilidad legislativa con base únicamente en la Cámara baja. Los datos del análisis están en poder del autor. 
partidos, incapaces de permanecer en el tiempo, y la necesidad de muchos de ellos de generar coaliciones con otras organizaciones para poder entrar al Congreso. En todo caso, este no es un valor sorprendente, ya que como Mainwaring y Zoco (2007) afirman, las democracias nacidas después de 1978, como es el caso de la peruana, han mostrado altos valores en este indicador, que se reduce además a expensas del desempeño económico, cuestión que razonablemente también sucede en Perú, al menos en los últimos quince años.

También a esto debe sumarse el irregular desempeño de los partidos de carácter nacional y tradicional en los comicios subnacionales, que han ido de un claro dominio en los años ochenta a una progresiva competencia de fuerzas independientes y regionales. Por ello, la nacionalización, al menos vista desde la conceptualización de autores como Schattschneider (1975), ${ }^{10}$ es limitada en Perú, dada la poca consonancia de resultados electorales entre los niveles nacional y subnacional, inclusive si se le compara con el resto de América Latina (Batlle, 2012, p. 63, aunque esta autora sitúa a Perú en un nivel intermedio comparativamente).

Seifert Bonifaz (2014, p. 107), por su parte, señala que, si bien en 2002 las elecciones regionales y municipales peruanas fueron dominadas por partidos nacionales, quienes obtuvieron conjuntamente alrededor del $60 \%$ de los votos, para 2010 su voto agregado se situó en el $25 \%$, dejando paso a organizaciones regionales. Para el mismo autor (2014, pp. 108-111), la carencia de confianza por parte de los ciudadanos hacia los partidos nacionales, la mayor exigencia que las leyes sobre partidos hacían a las organizaciones

10. Este autor considera la nacionalización del sistema de partidos en función de la consonancia de los resultados a escala nacional con las escalas subnacionales, es decir, su homogeneidad. Para más información en torno a este concepto, su aplicación y situación en América Latina, se recomienda: Dosek (20I5). 
nacionales vs. las subnacionales, y el peso de los líderes regionales provocaron el declive de las fuerzas nacionales.

Este desplazamiento también se observó en el ámbito nacional, pues las fuerzas tradicionales (APRA, PPC, AP e izquierda) fueron progresivamente sustituidas por nuevas organizaciones: el PP, el PNP, la UPP y el FIM, el fujimorismo a través de sus diversas marcas, como destaca Tanaka (2015, p. 171). Sin embargo, esta sustitución no fue completa, pues estas mismas nuevas organizaciones padecieron elevada volatilidad e incluso inestabilidad en cuanto a su ingreso al Legislativo, además de su ya mencionada creciente incapacidad para imponerse en comicios no nacionales.

A ello debe sumarse la tendencia que han mostrado los partidos políticos que han gobernado en Perú a obtener malos resultados en las elecciones generales subsecuentes. Desde 2001, todas las fuerzas oficialistas recibieron fuertes penalizaciones electorales tras su salida del poder, lo que además fue en consonancia con la baja calificación popular con que terminaron su mandato los presidentes. Esta situación se produjo independientemente de la institucionalización del partido y de la coyuntura económica, lo que lleva a Mas (2014) a entender que la no reelección es una importante variable explicativa, dado el peso de los líderes en las organizaciones políticas.

La elevada fragmentación partidaria, a su vez, dificultó la formación de mayorías parlamentarias por parte del Ejecutivo. De igual modo, de esta tendencia se puede interpretar que las modificaciones realizadas en la legislación electoral que buscaron una reducción de partidos con presencia parlamentaria y su estabilización han podido fracasar, tal y como muestran los datos y en línea con Tanaka (2006, p. 4).

Por todo ello, destaca el debate teórico en torno al sistema de partidos peruano. La personalización y peso de los líderes partidarios, así como la inestabilidad de las organizaciones 
partidarias, han llevado a muchos autores a considerar a Perú como un país sin sistema de partidos, hecho mencionado previamente. Sin embargo, el desempeño de los últimos años ha llevado a otros a cuestionar esta afirmación. En este último sentido se manifiesta Meléndez (2012, p. 24), cuando afirma que el sistema de partidos peruano más bien se encuentra "en un proceso de institucionalización tampoco previsto de acuerdo con los cánones establecidos". El mismo autor resalta ciertos indicadores interesantes para este debate, ya que, en los últimos años, a la decreciente volatilidad electoral se ha añadido un

alto componente ideológico como base de los vínculos políticos, un sistema político legitimado y la formación de identidades políticas. Efectivamente, si predominan las organizaciones personalistas, que son básicamente vehículos electorales de efímera existencia, hechas para la coyuntura electoral y a la medida del cliente, se esperaría la continuidad de altos niveles de volatilidad electoral (Meléndez, 2012, p. 8).

A esto ha de añadirse cierta estabilización en las candidaturas electorales, como se ha mostrado en los casos de Toledo, Humala, García y el fujimorismo, aunque con irregular desempeño electoral. En todo caso, Luna (2015, p. 28) considera que el sistema de partidos peruano es "inestable y no programático", lo que enfatiza los lazos personalistas y clientelares entre las organizaciones partidarias y los electores, en contraposición a Meléndez (2012), pero en línea a autores como Mainwaring y Torcal (2006).

Precisamente la elevada volatilidad agregada, aunque tendente a la baja, es un indicador de baja institucionalización del sistema de partidos, siguiendo a Mainwaring y Scully (1995). Resulta interesante que, a pesar de la baja institucionalización del sistema de partidos peruano, los votantes puedan mantener información e identificación ideológica de forma razonable con respecto a los partidos 
políticos que se presentan a las elecciones legislativas, lo que cuestiona la teoría en torno a los efectos de la baja institucionalización del sistema de partidos.

En efecto, tomando la definición de diversos autores para la medición de la institucionalización del sistema de partidos, el peruano estaría en valores bajos, dada la poca estabilidad y regularidad de los patrones de competición entre las organizaciones partidarias; el escaso enraizamiento de estas organizaciones en la sociedad; la no elevada legitimidad de los partidos ante la sociedad; y la preeminencia de organizaciones partidarias como meros vehículos electorales más que como partidos bien organizados y estructurados a nivel interno (Mainwaring y Scully, 1995). Por ello, aunque autores como Meléndez (2012) advierten que algunos elementos propios de la institucionalización se encuentran en el sistema peruano, en términos generales se trata de un sistema de baja institucionalización, como las investigaciones de Tanaka (2005b y 2006) y Ocampo Corrales y Sparrow Alcázar (2013) atestiguan.

Fernando Tuesta (2008), por su parte, destaca la elevada fragmentación partidaria y la incapacidad de los partidos políticos para agregar intereses ciudadanos a sus filas, lo que potencia la dependencia con respecto a sus líderes ( $p$. 129). A ello, el autor añade los efectos que detecta del voto preferencial, como las campañas personalistas de los candidatos y el intento en ocasiones de estos de desmarcarse de su organización partidaria e incluso del grupo parlamentario una vez que llegan al Congreso (p. 129).

Todo ello va acompañado de una visión negativa de los ciudadanos hacia los partidos y las instituciones políticas en general, ya que, como han ido mostrando regularmente los estudios de opinión como el Latinobarómetro, Perú tiende a situarse en las últimas posiciones de confianza hacia las organizaciones partidarias y el Congreso (Tanaka y Vera, 2010, p. 88). 


\section{El presidencialismo moderado peruano y su sistema} de partidos: ¿la parlamentarización del sistema?

Como se ha visto hasta ahora, el sistema presidencial peruano contiene características reseñables que pueden determinar las relaciones entre los poderes Ejecutivo y Legislativo, especialmente respecto a los poderes en torno a la disolución del Congreso y la existencia de un PCM que requiere de la confianza de los diputados. A ello debe agregarse un sistema de partidos fragmentado, volátil, inestable y poco institucionalizado, con frecuentes minorías oficialistas en la Cámara baja. Por tanto, emerge una pregunta de investigación: ¿cómo incidió todo ello en las relaciones entre el Ejecutivo y el Legislativo entre 2001 y 2016 ?

\section{I. Grupos parlamentarios y composición del Consejo de Ministros}

A lo largo el periodo de estudio, el Congreso de la república fue reflejo de la volatilidad que caracterizó al sistema de partidos. Los presidentes no lograron mayorías oficialistas en la Cámara de manera estable, y su grupo parlamentario no alcanzó mayoría absoluta en ninguno de los quince periodos anuales analizados, como se puede ver en la Tabla 1.

Ciertamente, hay que tomar en cuenta los apoyos con los que contaron de manera estable en el Legislativo cada uno de estos grupos parlamentarios. Para el caso del presidente Alejandro Toledo, su principal y más constante alianza se estableció con el FIM, liderado por Fernando Olivera, aunque con apenas siete escaños en el inicio del quinquenio presidencial. Posteriormente, Alan García se ayudó de una mayor disciplina en su grupo parlamentario, además de combinarla con acuerdos coyunturales con varias fuerzas, entre ellas el fujimorismo (trece escaños) y Unidad Nacional (entre trece y diecisiete escaños). Finalmente, 
Tabla 1. Evolución de los grupos parlamentarios oficialistas

\begin{tabular}{|c|c|c|c|}
\hline$A \tilde{n} o$ & $\begin{array}{l}\text { Grupo } \\
\text { parlamentario }\end{array}$ & Número de escaños & $\begin{array}{c}\% \text { sobre total } \\
\text { escaños }\end{array}$ \\
\hline $\begin{array}{l}\text { 2001(inicio } \\
\text { mandato) }\end{array}$ & Perú Posible (PP) & $\begin{array}{l}\text { Cuarenta y siete } \\
\text { (sobre ciento veinte) }\end{array}$ & $39.1 \%$ \\
\hline $\begin{array}{l}2006 \text { (fin } \\
\text { mandato) }\end{array}$ & & $\begin{array}{l}\text { Treinta y dos } \\
\text { (sobre ciento veinte) }\end{array}$ & $26.1 \%$ \\
\hline $\begin{array}{l}2006 \text { (inicio } \\
\text { mandato) }\end{array}$ & APRA & $\begin{array}{l}\text { Treinta y seis } \\
\text { (sobre ciento veinte) }\end{array}$ & $27.6 \%$ \\
\hline $\begin{array}{l}2011 \text { (fin } \\
\text { mandato) }\end{array}$ & & $\begin{array}{l}\text { Treinta y seis } \\
\text { (sobre ciento veinte) }\end{array}$ & $27.6 \%$ \\
\hline $\begin{array}{l}2011 \text { (inicio } \\
\text { mandato) }\end{array}$ & $\begin{array}{l}\text { Nacionalista Gana } \\
\text { Perú (PNP) }\end{array}$ & $\begin{array}{l}\text { Cuarenta y siete } \\
\text { (sobre ciento treinta) }\end{array}$ & $36.1 \%$ \\
\hline $\begin{array}{l}2016 \text { (fin } \\
\text { mandato) }\end{array}$ & & $\begin{array}{l}\text { Veintiséis } \\
\text { (sobre ciento treinta) }\end{array}$ & $20 \%$ \\
\hline
\end{tabular}

Fuente: elaboración propia.

el nacionalismo peruano, liderado por Ollanta Humala y Nadine Heredia, tuvo muchas dificultades para mantener unido el grupo parlamentario, siendo reducido a poco más de la mitad en el último año del quinquenio presidencial, esto principalmente por la salida del sector más izquierdista, capitaneado por Verónika Mendoza.

Esta dificultad de las fuerzas oficialistas para lograr mayorías parlamentarias se acompañó durante los quince años analizados de una tendencia general hacia la inestabilidad en la composición de las bancadas congresuales. Por la disposición de sus elementos en forma gráfica, la Tabla 2 permite generar dos importantes conclusiones: resulta elevado el número de grupos parlamentarios para un Congreso de entre ciento veinte (hasta 2011) y ciento treinta escaños, y estos han sido inestables, ya que dentro de cada quinquenio se produjeron cambios apreciables, incluso en periodos anuales de sesiones. 
Tabla 2. Evolución del NEPP por periodo anual de sesiones

\begin{tabular}{lccc} 
Año & NEPP & Año & NEPP \\
2001 & 4.37 & $2010-2011$ & 5.76 \\
2006 & 6.06 & $2011-2012$ & 3.41 \\
$2006-2007$ & 3.99 & $2012-2013$ & 3.8 \\
$2007-2008$ & 5.37 & $2013-2014$ & 4.02 \\
$2008-2009$ & 6.01 & $2014-2015$ & 4.02 \\
$2009-2010$ & 5.99 & $2015-2016$ & 5.81 \\
\hline
\end{tabular}

Fuente: elaboración propia.

En efecto, como puede apreciarse, la salida de congresistas de los grupos parlamentarios para conformar nuevas bancadas fue una constante en el periodo bajo estudio, destacando como ejemplos de estabilidad el APRA y el fujimorismo - este último en mucha menor medida-. Las restantes fuerzas políticas vivieron numerosas modificaciones en su composición, lo que dibujó un Congreso altamente fragmentado y con crecientes dificultades para alcanzar mayorías, ya fueran en torno al oficialismo o como oposición.

¿Se reflejó esta inestabilidad en el Consejo de Ministros? Una lectura rápida vuelve a confirmar este patrón. Entre 2001 y 2016, se contabilizaron diecisiete PCM, es decir, la media de la duración en el cargo no alcanzó los doce meses. Como se puede observar en la Tabla 3, esta brevedad se dio en los tres mandatos presidenciales analizados, sin que la afiliación partidista de los mismos fuera una constante.

El motivo más frecuente de salida de los PCM fue su dimisión por mala gestión de eventos políticos, o bien, la amenaza de una moción de censura presentada por el Congreso, mecanismo que sólo en una ocasión logró cesar de manera directa a un PCM. En todo caso, resulta subrayable esta frecuente pérdida de confianza por parte del Legislativo, dada la necesidad de los PCM de iniciar su mandato con el voto mayoritario de dicho poder. 
El poder de veto de este órgano, siguiendo la terminología de Tsebelis (1995), se manifestó de manera directa pero inesperada por ser el peruano un sistema presidencialista. Es posible que la respuesta a esta situación se fundamente parcialmente en la necesidad de que el PCM sea propuesto por el presidente de la república, y no por el Legislativo, a semejanza del sistema francés. Es decir, los PCM fueron frecuentemente cesados de su cargo dada su identificación con el jefe del Estado y, a la vez, su dependencia de un Congreso con minoría oficialista.

Tabla 3. Presidentes del Consejo de Ministros (2001-2016)

\begin{tabular}{|c|c|c|c|}
\hline Nombre & $\begin{array}{l}\text { Duración en el } \\
\text { cargo }\end{array}$ & $\begin{array}{l}\text { Afiliación } \\
\text { partidaria* }\end{array}$ & Forma de salida \\
\hline $\begin{array}{l}\text { Roberto Dañino } \\
\text { Zapata }\end{array}$ & Once meses y medio & No & Cesado \\
\hline $\begin{array}{l}\text { Luis Solari de la } \\
\text { Fuente }\end{array}$ & $\begin{array}{l}\text { Once meses y una } \\
\text { semana }\end{array}$ & $\mathrm{PP}$ & Cesado \\
\hline $\begin{array}{l}\text { Beatriz Merino } \\
\text { Lucero }\end{array}$ & $\begin{array}{l}\text { Cinco meses y } \\
\text { medio }\end{array}$ & No & Dimisión \\
\hline $\begin{array}{l}\text { Carlos Ferrero } \\
\text { Costa }\end{array}$ & $\begin{array}{l}\text { Un año y cuatro } \\
\text { meses }\end{array}$ & $\mathrm{PP}$ & Dimisión \\
\hline $\begin{array}{l}\text { Pedro Pablo } \\
\text { Kuczynski }\end{array}$ & Once meses y medio & No & Fin de mandato \\
\hline $\begin{array}{l}\text { Jorge del Castillo } \\
\text { Gálvez }\end{array}$ & $\begin{array}{l}\text { Dos años y tres } \\
\text { meses }\end{array}$ & APRA & $\begin{array}{l}\text { Cese por } \\
\text { corrupción }\end{array}$ \\
\hline $\begin{array}{l}\text { Yehude Simon } \\
\text { Munaro }\end{array}$ & Diez meses & $\begin{array}{l}\text { Partido } \\
\text { Humanista }\end{array}$ & $\begin{array}{l}\text { Cese por su } \\
\text { gestión }\end{array}$ \\
\hline $\begin{array}{l}\text { Javier Velásquez } \\
\text { Quesquén }\end{array}$ & Catorce meses & APRA & Dimisión \\
\hline $\begin{array}{l}\text { José Antonio } \\
\text { Chang }\end{array}$ & Seis meses & APRA & $\begin{array}{l}\text { Motivos } \\
\text { personales }\end{array}$ \\
\hline Rosario Figueroa & Cuatro meses & $\begin{array}{l}\text { APRA, pero } \\
\text { no activa }\end{array}$ & Fin de mandato \\
\hline $\begin{array}{l}\text { Salomón Lerner } \\
\text { Ghitis }\end{array}$ & $\begin{array}{l}\text { Cuatro meses y } \\
\text { medio }\end{array}$ & $\begin{array}{l}\text { Partido } \\
\text { aliado }\end{array}$ & Dimisión \\
\hline
\end{tabular}




\begin{tabular}{|c|c|c|c|}
\hline Nombre & $\begin{array}{l}\text { Duración en el } \\
\text { cargo }\end{array}$ & $\begin{array}{l}\text { Afiliación } \\
\text { partidaria* }\end{array}$ & Forma de salida \\
\hline $\begin{array}{l}\text { Oscar Valdés } \\
\text { Dancuart }\end{array}$ & Siete meses & No & Dimisión \\
\hline $\begin{array}{l}\text { Juan Jiménez } \\
\text { Mayor }\end{array}$ & $\begin{array}{l}\text { Un año y tres } \\
\text { meses }\end{array}$ & No & Dimisión \\
\hline $\begin{array}{l}\text { César Villanueva } \\
\text { Arévalo }\end{array}$ & Cuatro meses & No & Dimisión \\
\hline René Cornejo Díaz & Cinco meses & No & Cesado-dimisión \\
\hline $\begin{array}{l}\text { Ana Jara } \\
\text { Velásquez }\end{array}$ & Diez meses & PNP & $\begin{array}{l}\text { Moción de } \\
\text { censura }\end{array}$ \\
\hline $\begin{array}{l}\text { Pedro Cateriano } \\
\text { Bellido }\end{array}$ & $\begin{array}{l}\text { Un año y cuatro } \\
\text { meses }\end{array}$ & No & Fin de mandato \\
\hline
\end{tabular}

* Al momento de asumir el cargo.

Fuente: elaboración propia.

Con respecto a los ministros, se observa una inestabilidad similar, ya que las salidas de los PCM fueron a menudo aprovechadas por los presidentes de la república para reordenar el gabinete en busca de nuevos apoyos parlamentarios. Esto, unido a las dimisiones ministeriales fuera de estas crisis políticas, arroja una estadía media de trece meses por cada ministro en la cartera original. Esta elevada rotación de ministros y primeros ministros por debilidad del Ejecutivo en el Congreso de la república lleva a considerar al Legislativo como poder beneficiario de la fragmentación e inestabilidad de los grupos parlamentarios.

Es decir, la facultad legislativa de cesar a ministros y primeros ministros fue empleada indirectamente a pesar de la potencial contraparte ejecutiva (la disolución del Congreso por parte del presidente de la república, quien no la llevó a emplear). Por tanto, a pesar de que el diseño institucional peruano conlleva cierta dependencia mutua de los poderes, al estilo del parlamentarismo (Stepan y Skach, 1993, p. 3), el Congreso logró fomentar la inestabilidad del Ejecutivo, 
y cuando este estuvo habilitado para emplear la disolución del Legislativo, no lo hizo.

Asimismo, estas características institucionales, en combinación con el sistema de partidos, van en consonancia con las tesis de Mainwaring (1993), Hochstetler (2006) y Chasquetti (2001). En efecto, la aparente separación rígida de los poderes que el presidencialismo establece en su origen no es obstáculo para que la minoría parlamentaria del oficialismo, bajo escenarios de multipartidismo e incapacidad de generar coaliciones estables, pueda propiciar la debilidad del Ejecutivo en su composición.

Esta fue la situación del periodo de estudio analizado. Por otra parte, Collor de Mello (en 1992) y Dilma Rousseff (en 2016) en Brasil, así como PPK (2018) en Perú tuvieron que enfrentar legislaturas de fuerte carácter opositor con sus minorías parlamentarias, terminando los tres casos con su salida de la Presidencia. En cambio, Alan García y Fujimori pudieron evitar cargos formales desde el Congreso peruano precisamente por su fortaleza partidaria (Hochstetler, 2006, p. 408).

No obstante, esto último no debe entenderse en la línea de las investigaciones de Mainwaring (1993) y Linz (1990 y 1998), ya que precisamente esta inestabilidad del Ejecutivo podría reducir los enfrentamientos entre ambos poderes, suponiendo cierto reacomodo de las relaciones entre las fuerzas partidarias y no la conformación de incentivos para el quiebre democrático. Ha de subrayarse que el diseño institucional peruano establece ciertos mecanismos, ya mencionados, para el control y el equilibrio entre Ejecutivo y Legislativo.

\subsection{La producción legislativa en Perú y el uso del decreto}

Con base en Levitt (2012, p. 169), es posible decir que el $35 \%$ de las leyes aprobadas durante el mandato de Alejandro Toledo procedieron del Ejecutivo. Patriau (2012, p. 6) indica 
que en el quinquenio de Alan García dicho porcentaje fue del 42.3\%, y, según datos del Congreso, de 40.6\% durante el Gobierno de Ollanta Humala.

Con respecto a los mandatarios previos, Levitt (2012, p. 169) resume la información de otras investigaciones, y señala que durante el primer mandato de García, entre el $21 \%$ y el $31 \%$ de las leyes publicadas partieron del Ejecutivo; 19\% durante el primer bienio de Fujimori (caracterizado por su minoría en el Parlamento y por un enfrentamiento abierto contra este poder); y, desde entonces y hasta el año 2000 (en que el fujimorismo ya tuvo dominio de la Cámara), un $76.1 \%$. Ciertamente, ha de reconocerse que el periodo 1992-2000 albergó peculiaridades que distorsionaron las relaciones entre el Ejecutivo y el Legislativo, aunque el marco normativo fuera, en términos generales, el mismo.

No obstante, y tomando en consideración estas cautelas, puede entenderse que la debilidad partidaria de los presidentes peruanos sí ha determinado su protagonismo en la producción legislativa. Por un lado, las mayorías en el Legislativo han favorecido, aparentemente, un elevado empleo del decreto, hecho que a su vez puede invitar a investigaciones futuras con respecto a las relaciones entre las bancadas oficialistas y el Ejecutivo.

Por otra parte, las minorías partidarias han supuesto más proyectos de ley en términos relativos, pero, sobre todo, más protagonismo del Congreso. A esto hay que sumar la gran diferencia de éxito legislativo que han mostrado los Ejecutivos en comparación a los grupos parlamentarios, ya que el Congreso tuvo una tasa promedio de éxito ${ }^{11}$ del $21.35 \%$ durante los quince años analizados, mientras que la del Ejecutivo fue de 62.4\%. Puede decirse que la variable partidaria influye, a la luz de los hechos, tanto en la can-

II. Se entiende como éxito legislativo la presentación de un proyecto de ley ante el Congreso y su publicación en el Diario Oficial El Peruano durante ese mismo quinquenio presidencial. 
tidad como en la composición de la producción normativa (Tabla 4).

Tabla 4. Decretos y leyes por mandato presidencial (1980-2016)

\begin{tabular}{lcccc} 
Presidente & $\begin{array}{c}\text { Decretos } \\
\text { legislativos }\end{array}$ & $\begin{array}{c}\text { Decretos de } \\
\text { urgencia }\end{array}$ & $\begin{array}{c}\text { Leyes } \\
\text { publicadas }\end{array}$ & Total \\
$\begin{array}{l}\text { Fernando Belaunde } \\
\text { (1980-1985) }\end{array}$ & 348 & 667 & 724 & 1739 \\
$\begin{array}{l}\text { Alan García } \\
\text { (1985-1990) }\end{array}$ & 263 & 1033 & 665 & 1961 \\
$\begin{array}{l}\text { Alberto Fujimori } \\
\text { (1990-2000) }\end{array}$ & 449 & 1813 & 1067 & 3329 \\
$\begin{array}{l}\text { Valentín Paniagua } \\
\text { (2000-2001) }\end{array}$ & 10 & 122 & 117 & 249 \\
$\begin{array}{l}\text { Alejandro Toledo } \\
\text { (2001-2006) }\end{array}$ & 42 & 205 & 1271 & 1517 \\
$\begin{array}{l}\text { Alan García } \\
\text { (2006-2011) }\end{array}$ & 142 & 383 & 732 & 1257 \\
$\begin{array}{l}\text { Ollanta Humala } \\
\text { (2011-2016) }\end{array}$ & 131 & 53 & 485 & 669 \\
Total & 1385 & 4276 & 5061 & 10721 \\
\hline
\end{tabular}

Fuentes: Levitt (2012, p. 172) para los datos hasta 2001; Tanaka y Vera (2010, p. 101) para datos hasta 2011. Los datos de 2011 a 2016 se obtuvieron del Departamento de Investigación y Documentación Parlamentaria, con información documental en poder del autor.

Igualmente, es destacable el uso del decreto legislativo, ya que requiere de una aprobación previa del Congreso por mayoría y para un tiempo y materia determinados. Es decir, el oficialismo ha de lograr suficientes apoyos parlamentarios para obtener la habilitación de la ley autoritativa. En este caso, puede observarse cómo la tendencia del uso de este mecanismo en el periodo de estudio es sensiblemente menor a la registrada en los años ochenta y noventa, donde el sistema de partidos era razonablemente diferente, en los ochenta por tener un carácter más estable e instituciona- 
lizado, y en los noventa por contar Fujimori con mayorías legislativas desde 1993.

A su vez, el empleo del decreto de urgencia ha tendido a ir a la baja, lo que ha concedido creciente protagonismo al Congreso como institución legisladora, especialmente si se contempla la relación creciente entre leyes y suma de decretos por periodo presidencial.

Dicho creciente protagonismo del Legislativo iría en línea con investigaciones como la de Chasquetti (2001), en un escenario donde el multipartidismo se combina con la minoría oficialista y dificulta a dicho poder un rol preponderante en sus relaciones con el Ejecutivo. El caso peruano lo muestra de manera efectiva tanto en la estabilidad gubernamental como en el decreciente rol legislador de la Presidencia.

\section{Conclusiones}

El presente estudio ha analizado las relaciones entre los poderes Ejecutivo y Legislativo en Perú durante el periodo 2001-2016, tomando en consideración el diseño institucional del presidencialismo peruano, así como su sistema de partidos, con baja institucionalización y recurrentes minorías oficialistas en el Congreso.

En este sentido, y a pesar de la separación de poderes que el presidencialismo establece en su diseño, ha de afirmarse que la existencia tanto de un PCM como de la facultad del Congreso de confirmarlo y cesarlo de su cargo ha potenciado al Legislativo en detrimento del Ejecutivo. La elevada rotación de ministros y primeros ministros sólo puede entenderse como una muestra de debilidad partidaria de los jefes de Estado, ya sea por una deficiente organización interna de sus organizaciones políticas, por la amenaza del Congreso de cesarlos, o por su rol menor en el Poder Ejecutivo. 
No obstante, durante los quince años analizados, sólo en una ocasión se presentó y se ganó una moción de censura por parte del Legislativo, aunque fueron numerosas las veces en las que el presidente de la república decidió precipitar las crisis de gabinetes para evitar llegar a las votaciones. Por tanto, el Congreso, aunque de diferente manera, también se vio afectado por la elevada fragmentación y dificultad de formar mayorías. A su vez, la debilidad del Ejecutivo contrasta con la aparente separación y rigidez del presidencialismo en su diseño institucional, lo que lleva a considerar a las especificidades del modelo peruano como unas de las principales variables explicativas de esta situación, junto al sistema de partidos.

Por otro lado, la producción legislativa muestra un desigual empleo del decreto entre los mandatarios analizados, aunque siempre en menor medida que quienes les precedieron durante los años ochenta y noventa. Este patrón se observa tanto en los decretos de urgencia como en los legislativos. Con respecto a la relación entre leyes y decretos, los primeros ganaron protagonismo relativo a medida que los presidentes de la república perdían apoyos congresuales, lo que destaca igualmente si se realiza una comparación con los mandatarios previos.

La variable que aparentemente ha podido incidir de mayor manera en este cambio de tendencia es, efectivamente, la partidaria. Como Mainwaring y Shugart (1997) advirtieron en el pasado, el presidencialismo puede verse afectado en su capacidad de gobernabilidad en entornos de partidos políticos poco estructurados e indisciplinados, hechos que encajarían con la inestabilidad de los grupos parlamentarios y la dificultad que las organizaciones partidarias mostraron para competir sin necesidad de acuerdos preelectorales. A este respecto, Toledo, García -en su segundo mandato- y Humala contaron con grupos parlamentarios que en ningún caso alcanzaron la mayoría en la Cámara de manera estable, 
aunado esto a las dificultades para mantener sus bancadas unidas -a excepción del aprismo durante la presidencia de García- y el fuerte castigo electoral que sufrieron sus organizaciones luego de sus presidencias.

Ha de afirmarse, pues, que la debilidad partidaria de los presidentes de la república en el periodo 2001-2016 ha concedido creciente protagonismo al Congreso en detrimento del Ejecutivo en materia de producción legislativa, y ha exacerbado la inestabilidad del Consejo de Ministros. El diseño institucional, por tanto, de un sistema de partidos fragmentado, de baja institucionalización y con minorías oficialistas ha propiciado cierta parlamentarización del presidencialismo peruano, lo que contrasta con el hiperpresidencialismo fujimorista de los años noventa, caracterizado por un diferente sistema de partidos y una personalidad más autoritaria que la que tuvieron quienes sucedieron a Fujimori en la Presidencia de la república.

No han de olvidarse las dificultades que encontraron los presidentes para llevar a cabo coaliciones partidarias en la Cámara baja. A pesar de que tanto Toledo como García tuvieron aliados estables (FIM y fujimorismo, respectivamente), no es menos cierto que se trataron de mayorías limitadas en contextos de muy baja valoración social hacia los jefes de Estado (y a las principales instituciones, de hecho), con baja organización partidaria y numerosos conflictos políticos. Las fuerzas no oficialistas no encontraron excesivos incentivos para apoyar al Ejecutivo, pero este tampoco supo o quiso generar mayorías estables en el Legislativo. Todo ello, no obstante, encaja con las tesis de Mainwaring (1993) sobre los efectos perniciosos del presidencialismo multipartidista, en línea con posteriores investigaciones (Linz, 1998; Colomer y Negretto, 2005; Cheibub, 2007), y en contra de otras (Pereira y Melo, 2012).

Por tanto, la combinación de una minoría oficialista, aunque no necesariamente con Gobierno dividido, mostró 
los efectos desestabilizadores de un sistema de partidos poco institucionalizado en regímenes presidencialistas con características parlamentarias, que limita la separación rígida de poderes y muestra una muy elevada rotación de ministros y primeros ministros, como ha sido el caso peruano. Se ha estado, por tanto, ante un sistema presidencial cuyo desempeño en el periodo analizado invita a considerarlo con rasgos parlamentarizados, dada la capacidad del Congreso de condicionar la estabilidad gubernamental y obtener un creciente rol legislador, en detrimento del Ejecutivo.

El determinante de todo esto, además del diseño institucional, debe encontrarse en el sistema de partidos, cuya baja institucionalización aparentemente afectó en Perú en mayor medida al Ejecutivo que al Legislativo, acompañado esto de un Congreso situado en la cima de sus pares latinoamericanos en cuanto a facultades de control y fiscalización (Alcántara, García Montero, y Sánchez López, 2005), a pesar de la mencionada capacidad del Ejecutivo de disolución parlamentaria, aparentemente más una amenaza que una realidad en la práctica política post Fujimori.

Alcántara, M. (2013). Sistemas políticos de América Latina. América del Sur.Volumen I. Madrid: Editorial Tecnos.

Alcántara, M., García Montero, M.,y Sánchez López, F. (2005). Funciones, procedimientos y escenarios: un análisis del Poder Legislativo en América Latina. Salamanca: Ediciones Universidad de Salamanca.

Batlle, M. (20I2). Sistemas de partidos multinivel en contextos unitarios en América Latina: los casos de Ecuador, Perú, Bolivia y Colombia (I978-20I I) [tesis doctoral inédita]. Universidad de Salamanca: Salamanca.

Chasquetti, D. (200I). "Democracia, multipartidismo y coaliciones en América Latina: evaluando la difícil combinación", en J. Lanzaro (comp.), Tipos de presi- 
Bibliografía dencialismo y coaliciones políticas en América Latina (pp. 319-359). Buenos Aires: CLACSO.

Cheibub, J. A. (2007). Presidentialism, Parliamentarism, and Democracy. Cambridge: Cambridge University Press.

Colomer, J. M., y Negretto, G. (2005). Can Presidentialism Work Like Parliamentarism? Government and Opposition. Oxford: Blackwell Publishing.

Contreras, C., y Zuloaga, M. (20 I4). Historia mínima del Perú. Madrid:Turner.

Dosek, T. (20I5). “La nacionalización de los partidos y sistemas de partidos en América Latina. Concepto, medición y reciente desarrollo de su estudio en la región". Política y gobierno, 22(2), 347-390. Recuperado de: http://www.politicaygobierno.cide.edu/index.php/ Pyg/article/view/684/573

García Belaunde, D. (2008). "Evolución y características del presidencialismo peruano". Ponencia presentada en el Encuentro del Instituto Iberoamericano de Derecho Constitucional. La democracia constitucional en América Latina y las evoluciones recientes del presidencialismo. Universidad Externado de Colombia, Bogotá.

García Belaunde, D. (2009). “El presidencialismo atenuado y su funcionamiento. Con referencia al sistema constitucional peruano", en J. Andrew Ellis, J. Orozco Henríquez, y D. Zovatto (coords.), Cómo hacer que funcione el sistema presidencial (pp. I I9-I36). Ciudad de México: UNAM.

García Montero, M. (2009). Presidentes y parlamentos: ¿quién controla la actividad legislativa en América Latina? Madrid: CIS.

Hochstetler, K. (2006).“Rethinking Presidentialism: Challenges and Presidential Falls in South America". Comparative Politics, 38(4), 40 I-418. Recuperado de: https://scholar. harvard.edu/files/levitsky/files/hochstetler.pdf 
Lanzaro,J.(20I2). Presidencialismo y parlamentarismo. América Bibliografía Latina y Europa meridional. Madrid: Centro de Estudios Políticos y Constitucionales.

Levitsky, S., y Cameron, M. (2003)."DemocracyWithout Parties? Political Parties and Regime Change in Fujimori's Peru”. LatinAmerican Politics and Society, 3(45), I-33. Recuperado de: https://www.jstor.org/stable/3 I77I57?seq= I\#metadata_ info_tab_contents

Levitsky, S., y Way, L. (2010). Competitive Authoritarianism: Hybrid Regimes after the Cold War. Cambridge: Cambridge University Press.

Levitt, B. (20I2). Power in the Balance. Presidents, Parties and Legislatures in Peru and Beyond. Indiana:University of Notre Dame Press.

Linz, J. J. (1990). “The Perils of Presidentialism”. Journal of Democracy, I ( I), 5 I-69. Recuperado de: https://scholar. harvard.edu/levitsky/files/ I. Ilinz.pdf

Linz, J. J. (1998). “Democracia presidencial o parlamentaria. ¿Qué diferencia implica?", en J. Linz, y A. Valenzuela (comps.), La crisis del presidencialismo (pp. I-69). Madrid: Alianza Universidad.

Luna, J. P. (2015). "Institucionalización de los sistemas de partidos: ipor qué es necesario un nuevo concepto?", en M. Torcal (coord.), Sistemas de partidos en América Latina. Causas y consecuencias de su equilibrio inestable (pp. 9-42). Barcelona:Anthropos Editorial.

Mainwaring,S.(1993).“Presidentialism, Multipartism, and Democracy:The Difficult Combination”. Comparative Political Studies, (26), I 98-228. doi: I 0. I I 77/00 I 04 I 4093026002003

Mainwaring, S., y Scully, T. (1995). "La institucionalización de los sistemas de partidos”. Revista de ciencia política, VXII(I-2), 63-I0I. Recuperado de: http://revistas.usal.es/ index.php/ I I30-2887/article/view/2442 
Bibliografía

Mainwaring, S., y Shugart, M.S. ( 1997).“Juan Linz, Presidentialism, and Democracy: A Critical Appraisal". Comparative Politics, 29(4), 449-47I.

Mainwaring, S., y Torcal, M. (2006). "Party system institutionalization and party system theory after the Third Wave of democratization", en R. Katz,yW. Crotty (eds.), Handbook of Political Parties (pp. 204-227). Londres: Sage Publications.

Mainwaring, S., y Zoco, E. (2007). "Secuencias políticas y estabilización de la competencia partidista: volatilidad electoral en viejas y nuevas democracias". América Latina hoy, (46), |47- I7I. Recuperado de: http://revistas.usal. es/index.php/ I I30-2887/article/view/2459

Mas, L. (20I4). "Ganar, gobernar y perder: aportes para entender el desempeño electoral de los partidos de Gobierno peruanos”. Politai: revista de ciencia política, 5(8), I 45-I54. Recuperado de: http://revistas.pucp.edu. pe/index.php/politai/article/view// 3885

Meléndez, C. (2006). "Perú. Partidos y outsiders. El proceso electoral peruano de 2006”. Desafios, (14), 40-68. Recuperado de: https://revistas.urosario.edu.co/index.php/ desafios/article/view/736/664

Meléndez, C. (20I2). Partidos inesperados. La institucionalización del sistema de partidos en un escenario de postcolapso partidario. Perú 200I-20II. Lima: Fundación Fiedrich Ebert.

Nohlen, D. (20 I 3). “El presidencialismo comparado”. Revista Instituto de Altos Estudios Europeos, (I), 6-23. Recuperado de: http://www.iaee.eu/riaee/num I/riaee lart I.pdf

Ocampo Corrales, D. B., y Sparrow Alcázar, B. (20 I 3). Institucionalidad y partidos políticos en el Perú. ¿Qué factores influyen sobre la probabilidad de la elección local de partidos institucionalizados? Lima: GRADE y CIES. 
Patriau, E. (20I2). El Congreso peruano en el proceso de políticas Bibliografía públicas: influencia informal sobre la burocracia. Salamanca: Instituto de lberoamérica.

Pease García, H. (20 I0). Cómo funciona el presidencialismo en el Perú. Lima: Pontificia Universidad Católica del Perú.

Pereira, C., y Melo, M.A. (20I2). “The Surprising Success of Multiparty Presidentialism”. Journal of Democracy, 23(3), 156-173. Recuperado de: https://www.researchgate.net/ profile/Carlos_Pereira I4/publication/2367425I0_The Surprising_Success_of_Multiparty_Presidentialism/ links/00b4952ced379322b5000000/The-SurprisingSuccess-of-Multiparty-Presidentialism.pdf

Rubio Correa, M. (1999). Estudio de la constitución política de 1993. Tomo IV. Lima: Pontificia Universidad Católica del Perú.

Sartori, G. (1996). Ingeniería constitucional comparada. Una investigación de estructuras, incentivos y resultados. Santiago de Chile: Fondo de Cultura Económica de Chile.

Schattschneider, E. (1975). The Semi-Sovereign People: A Realist's View of Democracy in America. Boston: Wadsworth.

Seifert Bonifaz, M. (20I4). Colapso de los partidos nacionales y auge de los partidos regionales. Lima:Pontificia Universidad Católica del Perú.

Stepan, A., y Skach, C. (1993). "Constitutional Frameworks and Democratic Consolidation: Parliamentarianism versus Presidentialism". World Politics, 46(I), I-22. Recuperado de: http://gsdrc.org/document-library/ constitutional-frameworks-and-democratic-consolidation-parliamentarianism-versus-presidentialism/

Tanaka, M. (1998). Los espejismos de la democracia. El colapso del sistema de partidos en el Perú, 1980-1995, en perspectiva comparada. Lima: Instituto de Estudios Peruanos.

Tanaka, M. (2002). "De la crisis al colapso de los sistemas de partidos y los retos de su reconstrucción: los casos de Perú 
Bibliografía

y Venezuela". Ponencia presentada en la conferencia The Crisis of Democratic Representation in the Andes. Helen Kellogg Institute for International Studies, University of Notre Dame, Notre Dame, Estados Unidos.

Tanaka, M. (2005a). “Los sistemas de partidos en los países andinos: autoritarismos competitivos y reformismo constitucional”, en K. Sample, y D. Zovatto (eds.), Democracia en la región andina, los telones de fondo (pp. I -60). Lima: IDEA.

Tanaka, M. (2005b). Democracia sin partidos: Perú, 2000-2005. Lima: Instituto de Estudios Peruanos.

Tanaka, M. (2006). El sistema de partidos "realmente existente" en el Perú. Los desafios de la construcción de una representación política nacional y cómo enrumbar la reforma política. Lima: Instituto de Estudios Peruanos.

Tanaka, M. (20I5)."Agencia y estructura, y el colapso de los sistemas de partidos en los países andinos", en M.Torcal (coord.), Sistemas de partidos en América Latina. Causas y consecuencias de su equilibrio inestable (pp. 16I-I82). Barcelona:Anthropos Editorial.

Tanaka, M., y Vera, R. (20 I0). “La dinámica 'neodualista' de una democracia sin sistema de partidos: la situación de la democracia en el Perú". Revista de ciencia política, 30(I), 87-1 I4. Recuperado de: https://repositorio. uc.cl/bitstream/handle/ I 534/ I I 26 I/000556 I 78 . pdf? sequence $=$ I \&isAllowed=y

Tsebelis, G.(1995).“'Decision Making in Political Systems: Veto Players in Presidentialism, Parliamentarism, Multicameralism and Multipartyism". British Journal of Political Science, 25(03), 289-325. Recuperado de: https://econpapers. repec.org/scripts/redir.pf?u=http $\% 3 \mathrm{~A} \% 2 \mathrm{~F} \% 2$ Fjournals. cambridge.org\%2Fabstract_S0007 I 23400007225; h=r epec:cup:bjposi:v:25:y:1 995:i:03:p:289-325_00 
Tuesta, F. (2005). "Sistemas electorales en la región andina", Bibliografía en K. Sample, y D. Zovatto (eds.), Democracia en la región andina, los telones de fondo (pp. 7I- I84). Lima: IDEA.

Tuesta, F. (2008). "Elecciones presidenciales Perú 2006", en M. Alcántara, y F. García Díez (coords.), Elecciones y política en América Latina (pp. 167-192). México: Instituto Electoral del Estado de México.

Tuesta, F. (20I0). El sistema de partidos en la región andina. Construcción y desarrollo (1978-1995). Lima: Asamblea Nacional de Rectores. 